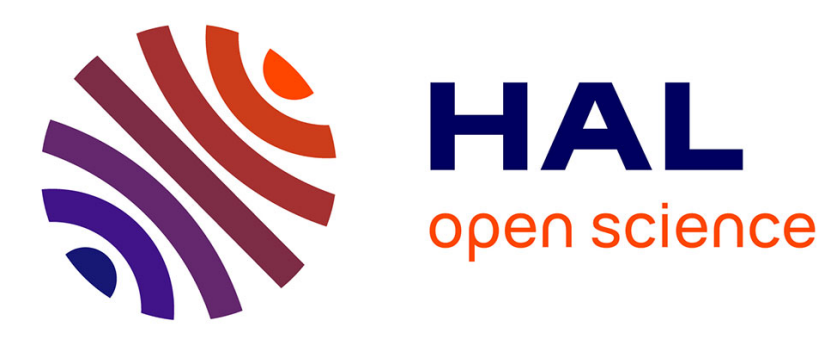

\title{
Imaging Native Calcium Currents in Brain Slices
}

Karima Ait Ouares, Nadia Jaafari, Nicola Kuczewski, Marco Canepari

\section{To cite this version:}

Karima Ait Ouares, Nadia Jaafari, Nicola Kuczewski, Marco Canepari. Imaging Native Calcium Currents in Brain Slices. Calcium Signaling, pp.73-91, 2020, Advances in Experimental Medicine and Biology, 10.1007/978-3-030-12457-1_4 . hal-02441768

\section{HAL Id: hal-02441768 https://hal.science/hal-02441768}

Submitted on 16 Jan 2020

HAL is a multi-disciplinary open access archive for the deposit and dissemination of scientific research documents, whether they are published or not. The documents may come from teaching and research institutions in France or abroad, or from public or private research centers.
L'archive ouverte pluridisciplinaire HAL, est destinée au dépôt et à la diffusion de documents scientifiques de niveau recherche, publiés ou non, émanant des établissements d'enseignement et de recherche français ou étrangers, des laboratoires publics ou privés. 
Adv Exp Med Biol, in press

\section{Imaging Native Calcium Currents in Brain Slices}

\section{Karima Ait Ouares ${ }^{\mathrm{a}, \mathrm{b}}$, Nadia Jaafari ${ }^{\mathrm{a}, \mathrm{b}}$, Nicola Kuczewski ${ }^{\mathrm{c}}$ and Marco Canepari ${ }^{\mathrm{a}, \mathrm{b}, \mathrm{d}}$}

a Univ. Grenoble Alpes, CNRS, LIPhy, F-38000 Grenoble, France

${ }^{b}$ Laboratories of Excellence, Ion Channel Science and Therapeutics, France.

${ }^{c}$ Centre de Recherche en Neurosciences de Lyon, INSERM U1028/CNRS UMR5292, Université Lyon1, Lyon, France

d Institut National de la Santé et Recherche Médicale (INSERM), France.

\section{Address of the submitting and corresponding author}

Marco Canepari, Laboratoire Interdisciplinaire de Physique (UMR 5588), Bat. E45, 140 avenue de la physique, Domaine univ., 38402 St Martin d'Hères cedex, France. Email: marco.canepari@univgrenoble-alpes.fr

Short Title: Imaging Native Calcium Currents

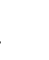

5

6

7

8


35

36 

6

\section{Abstract}

Imaging techniques may overcome the limitations of electrode techniques to measure locally not only membrane potential changes, but also ionic currents. Here, we review a recently developed approach to image native neuronal $\mathrm{Ca}^{2+}$ currents from brain slices. The technique is based on combined fluorescence recordings using low-affinity $\mathrm{Ca}^{2+}$ indicators possibly in combination with voltage sensitive dyes. We illustrate how the kinetics of $\mathrm{a} \mathrm{Ca}^{2+}$ current can be estimated from the $\mathrm{Ca}^{2+}$ fluorescence change and locally correlated with the change of membrane potential, calibrated on an absolute scale, from the voltage fluorescence change. We show some representative measurements from the dendrites of CA1 hippocampal pyramidal neurons, from olfactory bulb mitral cells and from cerebellar Purkinje neurons. We discuss the striking difference in data analysis and interpretation between $\mathrm{Ca}^{2+}$ current measurements obtained using classical electrode techniques and the physiological currents obtained using this novel approach. Finally, we show how important is the kinetic information on the native $\mathrm{Ca}^{2+}$ current to explore the potential molecular targets of the $\mathrm{Ca}^{2+}$ flux from each individual $\mathrm{Ca}^{2+}$ channel.

\section{Keywords:}

\section{Calcium currents}

Calcium imaging

Voltage sensitive dyes imaging

CA1 hippocampal pyramidal neuron

Olfactory bulb mitral cell

Purkinje neuron

Brain slices

Action potential

Synaptic potential

Biophysical modeling .

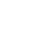

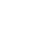

8

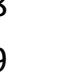

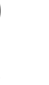
5 


\section{Introduction}

Optical measurements have been historically designed to monitor the electrical activity of the nervous system, a task where the use of electrode techniques has clear limitations (1). In the last two decades, the development of new organic voltage sensitive dyes (VSD), in parallel with the progress of devices to excite and detect fluorescence (2), allowed optical recordings of sub-cellular membrane potential $\left(\mathrm{V}_{\mathrm{m}}\right)$ changes $<1 \mathrm{mV}$ with a signal-to-noise ratio $(\mathrm{S} / \mathrm{N})$ comparable to that of patch clamp recordings (3). This achievement suggested that voltage imaging can be used to investigate voltagedependent proteins, in particular voltage-gated ion channels, in their physiological environment. The principal function of an ion channel is to allow an ion flux through a membrane, i.e. to produce an ionic current. Thus, the study of the biophysics of ion channels is routinely performed by measurements of ionic currents in single-electrode or two-electrode voltage clamp (4). A way to investigate the biophysics of isolated native ion channels is to perform excised patches from ex-vivo membranes (5). Alternatively, ion channels can be expressed in foreign cells such as oocytes or mammalian cell lines (6) and studied by using patch clamp techniques (7). Yet, the physiological role and function of voltage-gated ion channels must be investigated in their natural environment, i.e. in their native cellular compartment and during physiological changes of $V_{m}$. To this purpose, the voltage clamp electrode approach has serious limitations for several reasons. First, the ionic current is measured by maintaining the cell at a given artificial $V_{m}$ and even if the cell is dynamically clamped the $V_{m}$ change is never a physiological signal (8). Second, the current measured with the electrode is the summation of the filtered currents from all different cellular regions, including remote regions where $V_{m}$ is unclamped, and no information is available on the site of origin of the current (9). Third, different ionic currents contribute to the physiological change of $V_{m}$ producing a functional coupling among the different ion channels (10). Thus, a single native ionic current must be pharmacologically isolated from the total current mediated by the other channels, but the block of these channels will make the $\mathrm{V}_{\mathrm{m}}$ change non-physiological.

In the last few years, we designed a novel approach to measure physiological $\mathrm{Ca}^{2+}$ currents from neurons in brain slices (11). The method is based on fast $\mathrm{Ca}^{2+}$ optical measurements using lowaffinity indicators that can be combined with sequential (12) or simultaneous (13) $V_{m}$ optical recordings. The latter measurements can be calibrated in $\mathrm{mV}$ (14) using cell-specific protocols. Individual cells are loaded with $\mathrm{Ca}^{2+}$ and $\mathrm{V}_{\mathrm{m}}$ indicators using a patch clamp recording. In contrast to voltage-clamp current measurements, the current approach permits independent recordings of the $V_{m}$ change and of the $\mathrm{Ca}^{2+}$ influx, i.e. the study of voltage gating during physiological $\mathrm{V}_{\mathrm{m}}$ changes. Since the $\mathrm{Ca}^{2+}$ current is reconstructed by the measurement of $\mathrm{Ca}^{2+}$ locally binding to an indicator, this approach provides information on channels in different areas of the cell with a spatial resolution as good as the optical recording allows. Finally, the $\mathrm{Ca}^{2+}$ current is recorded without blocking all $\mathrm{Na}^{+}$and $\mathrm{K}^{+}$channels that are necessary to produce the physiological $\mathrm{V}_{\mathrm{m}}$ change. The principle of obtaining an optical measurement of a fast $\mathrm{Ca}^{2+}$ current is based on the analysis of the dye- $\mathrm{Ca}^{2+}$ binding reaction in a cell, a scenario initially studied by Kao and Tsien (15). According to their theoretical estimates 
and to our recent empirical measurements (16), the relaxation time of the dye- $\mathrm{Ca}^{2+}$ binding reaction is less than $200 \mu$ s for low-affinity indicators with equilibrium constant $\left(K_{D}\right) \geq 10 \mu M$ such as Oregon Green BAPTA-5N (OG5N, $\left.K_{D}=35 \mu \mathrm{M}, 17\right)$ or Fura-FF ( $\left.K_{D}=10 \mu \mathrm{M}, 18\right)$. Therefore, a fast $\mathrm{Ca}^{2+}$ current with duration of a few milliseconds can be reliably tracked by low-affinity indicators if fluorescence is acquired at sufficiently high speed. The goal of this methodological article is to provide an exhaustive tool for those scientists aiming at performing this type of measurement. The next section addresses in detail the problem of extracting the $\mathrm{Ca}^{2+}$ current kinetics from $\mathrm{Ca}^{2+}$ fluorescence measurements under different cellular buffering conditions. The following section is devoted to the technical aspects of how to set up combined $V_{m}$ and $\mathrm{Ca}^{2+}$ optical measurements and to calibrate $\mathrm{V}_{\mathrm{m}}$ signals on an absolute scale. We then illustrate some examples of combined $\mathrm{V}_{\mathrm{m}}$ and $\mathrm{Ca}^{2+}$ current measurements and we finally discuss how to correctly interpret the results and how to use this information to significantly advance our knowledge on $\mathrm{Ca}^{2+}$ channels function. All data shown here were from experiments performed at the Laboratoire Interdisciplinaire de Physique and approved by the Isere prefecture (Authorisation n. 3812 01). These experiments were performed at $32-34^{\circ} \mathrm{C}$ using brain slices from 21-40 postnatal days old C57BI6 mice of both genders.

\section{Extracting $\mathrm{Ca}^{2+}$ current kinetics from $\mathrm{Ca}^{2+}$ fluorescence measurements}

\subsection{Biophysical foundations of $\mathrm{Ca}^{2+}$ currents imaging}

An optical measurement of $\mathrm{C} \mathrm{Ca}^{2+}$ signal is ultimately a measurement of the $\mathrm{Ca}^{2+}$ indicator bound to $\mathrm{Ca}^{2+}$ ions, which is proportional to the $\mathrm{Ca}^{2+}$ fractional change of fluorescence $\left(\Delta \mathrm{F} / \mathrm{F}_{0}\right)$ if the indicator is not saturated. If the kinetics of the $\mathrm{Ca}^{2+}$-binding reaction of the indicator is slower than the kinetics of the $\mathrm{Ca}^{2+}$ source, and imaging is performed at higher rate, the time-course of $\mathrm{Ca}^{2+} \Delta \mathrm{F} / \mathrm{F}_{0}$ essentially tracks the kinetics of the chemical reaction. Alternatively, if the kinetics of the $\mathrm{Ca}^{2+}$-binding reaction is faster than the kinetics of the $\mathrm{Ca}^{2+}$ source, the $\mathrm{Ca}^{2+} \Delta \mathrm{F} / \mathrm{F}_{0}$ signal tracks the kinetics of the $\mathrm{Ca}^{2+}$ source. It follows that the equilibration (or relaxation) time of the $\mathrm{Ca}^{2+}$-indicator binding reaction is a crucial variable to use the technique to investigate the biophysics and the physiology of the $\mathrm{Ca}^{2+}$ source. The relaxation of the $\mathrm{Ca}^{2+}$ - binding reactions for early indicators was studied by Kao and Tsien (15) who established that the rate of association for all these molecules is limited by diffusion leading to an association constant of $\sim 6 \cdot 10^{8} \mathrm{M}^{-1} \mathrm{~s}^{-1}$. Thus, both the equilibrium constant $\left(\mathrm{K}_{\mathrm{D}}\right)$ and the equilibrium time are determined by the dissociation constant, i.e. the lower is the affinity of the indicator the shorter is its equilibrium time. We have empirically demonstrated that indicators with $K_{D} \geq$ $10 \mu \mathrm{M}$ such as OG5N or FuraFF have relaxation time $<200 \mu \mathrm{s}$ (16). Since the kinetics of activation and deactivation of voltage-gated $\mathrm{Ca}^{2+}$ channels (VGCCs) during physiological changes of $\mathrm{V}_{\mathrm{m}}$ (for instance action potentials), is governed by the kinetics of the $V_{m}$ transient, it follows that the relaxation time for those indicators is shorter than the duration of the $\mathrm{Ca}^{2+}$ influx. Hence, since $\mathrm{Ca}^{2+}$ binds to the indicator linearly in time, the $\mathrm{Ca}^{2+} \Delta \mathrm{F} / \mathrm{F}_{0}$ is proportional to the integral of the $\mathrm{Ca}^{2+}$ influx, i.e. to the 
integral of the $\mathrm{Ca}^{2+}$ current. In the cell, however, $\mathrm{Ca}^{2+}$ simultaneously binds to proteins that form the endogenous buffer and this binding is competing with the binding to the indicator. An endogenous buffer can be, in principle, at least as fast as the indicator in equilibrating. In this case, only a fraction of $\mathrm{Ca}^{2+}$ is bound to the indicator, but this fraction is proportional to the total $\mathrm{Ca}^{2+}$ entering the cell and therefore to the integral of the $\mathrm{Ca}^{2+}$ current. Alternatively, an endogenous buffer can equilibrate over a time scale that is longer than the duration of the $\mathrm{Ca}^{2+}$ current. In this case, $\mathrm{Ca}^{2+}$ first binds to the dye and later to the endogenous buffer, implying that part of $\mathrm{Ca}^{2+}$ moves from the indicator to the endogenous buffer during its relaxation time. Under this condition, the $\mathrm{Ca}^{2+} \Delta \mathrm{F} / \mathrm{F}_{0}$ is not linear with the integral of the $\mathrm{Ca}^{2+}$ current over this time scale. To clarify this important concept we make use of two simple computer simulations shown in Fig. 1, produced by a model that takes into account the chemical reactions as well as an extrusion mechanism re-establishing the initial $\mathrm{Ca}^{2+}$ conditions over a time scale $>100 \mathrm{~ms}$. We analyse what hypothetically can happen if a $\mathrm{Ca}^{2+}$ current with Gaussian shape occurs in a cell filled with 2 mM OG5N. In the first simulation (Fig. 1a), the cell has only $1 \mathrm{mM}$ of a fast endogenous buffer behaving with the same association constant of the indicator and $K_{D}=10$ $\mu \mathrm{M}$. In the second simulation (Fig. 1b), the cell has additional $400 \mu \mathrm{M}$ of a slower endogenous buffer with association rate $\sim 3$ times slower than that of the indicator and $K_{D}=0.2 \mu \mathrm{M}$. In the first case, the time derivative of the $\mathrm{Ca}^{2+} \Delta \mathrm{F} / \mathrm{F}_{0}$ signal matches the kinetics of the $\mathrm{Ca}^{2+}$ current (Fig. 1a). In contrast, in the presence of the slower buffer, the time derivative of the $\mathrm{Ca}^{2+} \Delta \mathrm{F} / \mathrm{F}_{0}$ signal has a negative component and does not match the kinetics of the $\mathrm{Ca}^{2+}$ current (Fig. 1b). In the next two paragraphs, we present the analysis strategies that can be applied to extract the kinetics of $\mathrm{Ca}^{2+}$ currents from $\mathrm{Ca}^{2+}$ imaging recordings.

\subsection{The case of linearity between $\mathrm{Ca}^{2+}$ influx and $\mathrm{Ca}^{2+}$ fluorescence changes}

The proteins expressed in a cell determine whether or not the time course of the $\mathrm{Ca}^{2+} \Delta \mathrm{F} / \mathrm{F}_{0}$ signal is linear with the kinetics of the $\mathrm{Ca}^{2+}$ current. As previously demonstrated (11), in the case of linear behaviour, the $\mathrm{Ca}^{2+} \Delta \mathrm{F} / \mathrm{F}_{0}$ signal must reach its peak and remain constant for a few milliseconds afterwards, i.e. for the entire duration of the current. As shown in the simulation of Fig. 1a, the kinetics of $\mathrm{Ca}^{2+}$ extrusion producing a slow decrease of the $\mathrm{Ca}^{2+} \Delta \mathrm{F} / \mathrm{F}_{0}$ signal has negligible effect on the time derivative. Thus, the estimate of the $\mathrm{Ca}^{2+}$ current kinetics is reliably obtained by the calculation of the time derivative of the $\mathrm{Ca}^{2+} \Delta \mathrm{F} / \mathrm{F}_{0}$ signal. This calculation, however, requires the signal noise to be smaller than the signal change between two consecutive samples. The classical way to achieve this necessary condition is to apply to the $\mathrm{Ca}^{2+} \Delta \mathrm{F} / \mathrm{F}_{0}$ signal a "smoothing algorithm", i.e. a temporal filter that reduces the noise of the signal with minimal distortion of its kinetics. At $20 \mathrm{kHz}$ acquisition rate, we have found that the Savitky-Golay algorithm (19) is an optimal filtering tool permitting noise reduction of the signal without significant temporal distortion using time-windows of up to 20-30 samples (11). The applicability of this strategy has however limitations, i.e. if the signal or the region of measurement are too small, or if the light is too dim, the smoothing of the signal might not be sufficient to reduce the noise down to the level permitting calculation of the time derivative. In this 
case, the alternative strategy to apply consists in fitting the raw or the filtered $\mathrm{Ca}^{2+} \Delta \mathrm{F} / \mathrm{F}_{0}$ signal with a model function obtaining a noiseless curve that mimics the time course of the $\mathrm{Ca}^{2+} \Delta \mathrm{F} / \mathrm{F}_{0}$ signal. $\mathrm{A}$ simple choice of function that resembles the time course of the $\mathrm{Ca}^{2+} \Delta \mathrm{F} / \mathrm{F}_{0}$ transient is the sigmoid. In particular, we found that the product of three sigmoid functions always provides an excellent fit of the $\mathrm{Ca}^{2+} \Delta \mathrm{F} / \mathrm{F}_{0}$ signal associated with a backpropagating action potential in CA1 hippocampal pyramidal neurons (16). As shown in the example of Fig. 2a both strategies are faithful in correctly calculating the time derivative of the $\Delta \mathrm{F} / \mathrm{F}_{0}$ signal. In this example, a $\mathrm{CA} 1$ hippocampal pyramidal neuron was filled with $2 \mathrm{mM} \mathrm{OG} 5 \mathrm{~N}$ and the dendritic $\mathrm{Ca}^{2+} \Delta \mathrm{F} / \mathrm{F}_{0}$ signal associated with a backpropagating action potential was recorded at $20 \mathrm{kHz}$ and averaged over 16 trials. This high sampling frequency was necessary to avoid signal aliasing and therefore distortion of the kinetics of the current. The filtering strategy is the straightforward approach that enables the calculation of the time derivative, but it produces a curve with noise. The noise can be reduced (if possible) by increasing the number of trials to average or by enlarging the dendritic area from where fluorescence is averaged. The fitting strategy is less direct but it produces a noiseless curve and it is therefore the only possible approach when the noise of the $\mathrm{Ca}^{2+} \Delta \mathrm{F} / \mathrm{F}_{0}$ signal is above a certain level, as quantitatively estimated in an original report (16). In particular, this is the case when the current must be extracted from single trials or when the recording is obtained from small or relatively dim regions.

\subsection{The case of nonlinearity between $\mathrm{Ca}^{2+}$ influx and $\mathrm{Ca}^{2+}$ fluorescence changes}

The method of estimating the kinetics of a $\mathrm{Ca}^{2+}$ current by calculating the $\mathrm{Ca}^{2+} \Delta \mathrm{F} / \mathrm{F}_{0}$ time derivative fails when $\mathrm{Ca}^{2+}$ unbinds from the indicator over a time scale that is longer than the current duration, but sufficiently short to distort the estimate of $\mathrm{Ca}^{2+}$ influx dynamics by fluorescence measurement. In other words, this method fails when the $\mathrm{Ca}^{2+} \Delta \mathrm{F} / \mathrm{F}_{0}$ signal decays rapidly, after correction for bleaching, generating a negative component in its time derivative. Such a situation occurs, for example, where slow buffering is produced by Calbindin-D28k $(20,21)$ and Parvalbumin $(22,23)$. As shown in the example of Fig. $2 \mathrm{~b}$, the $\mathrm{Ca}^{2+} \Delta \mathrm{F} / \mathrm{F}_{0}$ signal associated with a climbing fibre excitatory postsynaptic potential (EPSP), recorded at $5 \mathrm{kHz}$ from a dendritic region and averaged over four trials, decays rapidly after its maximum resulting in a negative component of its time derivative. The distortion from the linear behaviour produced by the slow buffers can be compensated by taking into account the kinetics of $\mathrm{Ca}^{2+}$ unbinding from the indicator. We have recently developed a successful method to achieve this goal (24). The strategy is based on fitting the decay time of the $\mathrm{Ca}^{2+} \Delta \mathrm{F} / \mathrm{F}_{0}$ signal with the result of a computer simulation of a model with a slow buffer. Initially the input current is the Gaussian function fitting the rising phase of the time derivative (that is still a good approximation of the initial part of the current). The kinetic parameters and the concentration of the slow buffer are set to obtain the best fit of the decay phase of the $\mathrm{Ca}^{2+} \Delta \mathrm{F} / \mathrm{F}_{0}$ signal. Then, the kinetics of the $\mathrm{Ca}^{2+}$ current is obtained as summation of four Gaussian functions that maximise the match between the result of the computer simulation and the experimental $\mathrm{Ca}^{2+} \Delta \mathrm{F} / \mathrm{F}_{0}$ signal. Although this new method provides only an indirect approximation of the kinetics of the $\mathrm{Ca}^{2+}$ current, this 
information is crucial at understanding the activation and deactivation of different types of VGCCs. In the dendrites of PNs, for instance, different $\mathrm{Ca}^{2+}$ current kinetics components are associated with the activation of P/Q-type VGCCs (25) and T-type $\mathrm{Ca}^{2+}$ channels (26) that can be in principle separated by pharmacological block of one component. Thus, the extrapolation of a curve that approaches the kinetics of the $\mathrm{Ca}^{2+}$ current can be used to quantitatively investigate the variability of channels activation at different dendritic sites, the modulation of channel activation due to physiological activity or to pharmacological action. Finally, it is important to say that such a strategy can be extended to estimate slower $\mathrm{Ca}^{2+}$ currents where the fitting procedure can be applied to the slower decay time due to $\mathrm{Ca}^{2+}$ extrusion (27).

\section{Combining membrane potential and $\mathrm{Ca}^{2+}$ Imaging}

\subsection{Setting up combined voltage and $\mathrm{Ca}^{2+}$ fluorescence measurements}

To combine $\mathrm{V}_{\mathrm{m}}$ and $\mathrm{Ca}^{2+}$ optical measurements, the VSD and the $\mathrm{Ca}^{2+}$ indicator must have minimal overlap in the emission spectra. Water soluble voltage indicators with different excitation and emission spectra have been recently developed (28). In particular, the red-excitable and IR emitting VSD ANBDQPTEA (or PY3283) is suitable for coupling with other optical techniques (29). Nevertheless, the most used VSDs for single cell applications are still JPW3028 (30) and the commercially available JPW1114 (18). These indicators have wide excitation spectrum in the blue/green region and they emit mainly in the red region. We have previously demonstrated that both indicators can be optimally combined with Fura indicators that are excited in the UV region and emit in the short green region (12). In this case, VSDs were excited at $543 \mathrm{~nm}$ using a laser and Fura indicators were excited at $385 \mathrm{~nm}$ using a light emitting diode (LED) as shown in the scheme of Fig.3a. Alternatively, simultaneous voltage and $\mathrm{Ca}^{2+}$ imaging can be achieved using Oregon Green, Calcium Green or Fluo $\mathrm{Ca}^{2+}$ indicators using blue light $(470-490 \mathrm{~nm})$ to excite both VSDs and $\mathrm{Ca}^{2+}$ indicators (31). Simultaneous imaging of JPW1114 and Oregon Green BAPTA-5N (OG5N) was adopted to obtain the first combined measurement of $\mathrm{V}_{\mathrm{m}}$ and $\mathrm{Ca}^{2+}$ currents using the configuration of Fig.3b. This type of measurement, however, has several disadvantages. First, OG5N fluorescence has a small tail component in the red region (31) which can be negligible or not depending on the ratio of the two dyes at each site as well as on the ratio between the two signals. Thus, for example, it works in proximal dendrites of CA1 pyramidal neurons for signals associated with action potentials (11), where $\mathrm{V}_{\mathrm{m}}$ fluorescence is stronger than $\mathrm{Ca}^{2+}$ fluorescence, but it does not in distal dendrites of cerebellar Purkinje neurons (PNs, data not shown), where $V_{m}$ fluorescence is weaker than $\mathrm{Ca}^{2+}$ fluorescence. A second disadvantage is that the JPW1114 signal at $470 \mathrm{~nm}$ excitation is $\sim 4$ times smaller than that at $532 \mathrm{~nm}$ excitation. If simultaneous recordings are not critical, one can replace them with sequential recordings obtained by alternating $470 \mathrm{~nm}$ and $532 \mathrm{~nm}$ excitation as used in a recent study (32). Finally, a third disadvantage is that JPW1114 absorbs more in the blue range than 
in the green range, i.e. it exhibits toxic effects after fewer exposures. A crucial technical aspect to take into consideration while setting up combined voltage and $\mathrm{Ca}^{2+}$ fluorescence measurements is the ability to record the two signals simultaneously at high speed. To this purpose, the company RedShirtlmaging (Decantur, GA) has developed a dual-head version of the SMQ NeuroCCD (Fig. 3c). This camera permits simultaneous image acquisitions from both heads at $5-20 \mathrm{kHz}$, i.e. at the required speed. A demagnifier developed by Cairn Research Ltd (Faversham, UK) allows adjusting the size of the image before it is split in two images at the emission wavelengths of the two dyes. Thus, the alignment of the two heads of the camera allows obtaining, at each precise region of interest, the $\mathrm{V}_{\mathrm{m}}$ and the $\mathrm{Ca}^{2+}$ signal.

\subsection{Calibrating membrane potential fluorescence transients}

The calibration of $\mathrm{V}_{\mathrm{m}}$ optical signals on an absolute scale (in $\mathrm{mV}$ ) is crucial to analyse the gating of $\mathrm{Ca}^{2+}$ channels at the same locations where $\mathrm{Ca}^{2+}$ recordings are performed. This is not, however, straightforward. Indeed, the fractional change of VSD fluorescence is proportional to $V_{m}(33)$, but the linear coefficient between these two quantities depends on the ratio between the inactive dye and the active dye that varies from site to site. The inactive dye is bound to membranes that do not change potential and contributes only to the resting fluorescence, while the active dye is bound to the plasma membrane and contributes to the resting fluorescence, but also carries the signal. In particular, in experiments utilising intracellular application of the dye, inactive dye is the dye that binds to intracellular membranes and organelles. Since the sensitivity of recording varies from site to site, a calibration can be achieved only if a calibrating electrical signal that has known amplitude at all locations is available. Such a signal is different in different systems. In mitral cells of the olfactory bulb, the amplitude of an action potential is the same in the whole apical dendrite and it can be used to create a sensitivity profile of the measuring system (34). Another type of calibrating electrical signal can be a slow electrical change spreading with minimal attenuation over relatively long distances. Such a signal can be used to reliably calibrate VSD signals in PNs (18). An example of this type of calibration is reported in Fig. 4a. Starting from the resting $V_{m}$, that we assume nearly uniform over the entire cell, long current hyperpolarising or depolarising current pulses are injected to the soma via the patch pipette and the change in $\mathrm{V}_{\mathrm{m}}$ is recorded. As shown by direct dendritic patch recording, the dendrite is hyperpolarised by the same amount of the soma (35). Thus, the measurement of somatic hyperpolarisation can be used as voltage reference to calibrate the dendritic VSD fractional change of fluorescence (VSD $\Delta F / F_{0}$ ) optical signal, as shown in Fig. 4a. In contrast, a depolarisation step attenuates along the dendrite. A third type of calibrating signal is a uniform depolarisation over the entire dendritic tree using L-glutamate photolysis from 4-Methoxy-7-nitroindolinyl-caged-L-glutamate (MNI-glutamate) (14). This calibration procedure is applicable to all membrane expressing a relatively large number of glutamate receptors, i.e. to dendrites with high densities of excitatory synapses. The calibration is based on the principle that if the ionotropic glutamate receptor becomes the dominant conductance in a particular neuronal compartment, its reversal potential will determine the membrane 
potential of the compartment. Thus, in the area where dominance of glutamate receptor conductance is obtained, the resulting $\mathrm{V}_{\mathrm{m}}$ change will be the same and can be used to calibrate VSD signals. An example of this protocol to calibrate backpropagating action potentials in CA1 hippocampal pyramidal neurons is shown in Fig. 4b. The VSD $\Delta F / F_{0}$ signal associated with the backpropagating $A P$ at different sites of the apical dendrites is variable and cannot be directly correlated with the absolute change of $V_{m}$. In the presence of $1 \mu \mathrm{M}$ TTX, to block action potentials, L-glutamate is photoreleased to saturate glutamate receptors over the whole field of view. Since the recording is performed starting from the resting $V_{m}$, the size of the $V S D \Delta F / F_{0}$ corresponds to this potential in the whole illuminated area where $V_{m}$ reaches the reversal potential of $0 \mathrm{mV}$. Thus, this information is used to extrapolate the $V_{m}$ at each dendritic site.

\section{Examples of combined voltage and $\mathrm{Ca}^{2+}$ current imaging}

\section{1 $\mathrm{Ca}^{2+}$ currents associated with backpropagating action potentials in CA1} hippocampal pyramidal neurons and in olfactory bulb mitral cells

In many neurons, action potentials generated in the axon hillock adjacent to the soma do not only propagate along the axon to reach neurotransmitter release terminals, but also backpropagate throughout dendrites to signal cell activation at the sites where the neuron receives the synaptic inputs. At least part of this information is given by the fast $\mathrm{Ca}^{2+}$ transients produced by activation of VGCCs caused by the dendritic depolarisation associated with the action potential. The analysis that can be performed using the present imaging method is therefore crucial at understanding signal processing in individual neurons, as well as the specific role and function of the diverse VGCCs activated in dendrites. The propagation of the action potential and the consequent activation of VGCCs may be very different in different neuronal systems. In CA1 hippocampal pyramidal neurons, action potentials attenuate along the dendrite and activate both high-voltage activated (HVA) and lowvoltage activated (LVA) VGCCs $(36,37)$. We have very recently demonstrated that HVA-VGCCs and LVA-VGCCs operate synergistically to stabilise $\mathrm{Ca}^{2+}$ signals during burst firing (32). Somatic and dendritic action potentials, at nearly physiological temperature, have 1-4 ms duration as in the example shown in Fig. 5a. In agreement with this, the kinetics of the $\mathrm{Ca}^{2+}$ current is similar to that of the action potential, with a peak delayed by a few hundred milliseconds from the peak of the action potential. In total contrast to the CA1 hippocampal pyramidal neuron, in olfactory bulb mitral cells the action potential does not attenuate along the dendrites (38). In addition, as shown in the representative example of Fig. 5b, the somatic and dendritic action potential at near physiological temperature $\left(32-34^{\circ} \mathrm{C}\right)$ has duration $<1 \mathrm{~ms}$. Thus, in this system, the activation and deactivation of VGCCs is also faster leading to a $\mathrm{Ca}^{2+}$ current with shorter duration and shorter delay from the $\mathrm{V}_{\mathrm{m}}$ waveform peak. This preliminary comparison between the two cases indicates that the role of VGCCs, activated by the action potential, is different in different systems. For example, $\mathrm{Ca}^{2+}$ currents 
with delays of $\sim 100 \mu \mathrm{s}$ in presynaptic terminal where the function of this signal is to trigger neurotransmitter release (39). Here, the kinetics of the $\mathrm{Ca}^{2+}$ current was obtained by calculating the time derivative of the $\mathrm{Ca}^{2+} \Delta \mathrm{F} / \mathrm{F}_{0}$ signal fit (16). VGCCs contribute to the shape of the action potential directly and indirectly by activating $\mathrm{K}^{+}$channels, but also provide a precise time-locked $\mathrm{Ca}^{2+}$ transient capable to select fast-activated $\mathrm{Ca}^{2+}$ binding proteins. The possibility to locally investigate, using combined $\mathrm{V}_{\mathrm{m}}$ and $\mathrm{Ca}^{2+}$ current optical measurements, the physiological occurrence of $\mathrm{Ca}^{2+}$ signals mediated by VGCCs will contribute enormously, in the near future, to the understanding of complex signal processing in neurons.

\section{2 $\mathrm{Ca}^{2+}$ currents associated with climbing fibre EPSPs in cerebellar Purkinje neurons}

In contrast to pyramidal neurons of the cortex and hippocampus, and to olfactory bulb mitral cells, somatic/axonal action potentials in PNs do not actively propagate in the dendrites (40). The dendrites of PNs, however, express P/Q-type HVA-VGCCs (25) and T-type LVA-VGCCs (26) that are activated by the dendritic depolarisation produced by climbing fibre EPSPs. As shown in the example of Fig. 6 , the shape of the dendritic $V_{m}$, calibrated in Fig. $4 a$ is quite different in the soma and in the dendrite, mainly reflecting the absence of $\mathrm{Na}^{+}$action potentials in the dendrite. In this system, the low-affinity $\mathrm{Ca}^{2+}$ indicator used to estimate the $\mathrm{Ca}^{2+}$ current was Fura-FF, since the larger $\mathrm{Ca}^{2+}$ signal produced by OG5N contaminated the optical $V_{m}$ measurement. The prominent dendritic depolarisation produces a biphasic $\mathrm{Ca}^{2+}$ current, which is in this case obtained by applying our recent generalised method (24). The fast and sharp component is nearly concomitant to the short period in which $V_{m}>-$ $40 \mathrm{mV}$ and it is therefore likely mediated by HVA-VGCCs. The slower and more persistent component is instead mostly concomitant to the whole depolarisation transient and is therefore likely mediated by LVA-VGCCs, as demonstrated by selectively blocking T-type VGCCs (unpublished data not shown). The analysis of $\mathrm{Ca}^{2+}$ signalling associated with the climbing fibre EPSP is crucial for the understanding of synaptic plasticity in $\mathrm{PNs}(41)$. Yet, while the role of the $\mathrm{Ca}^{2+}$ transient associated with the climbing fibre EPSP has been postulated to be auxiliary to the principal $\mathrm{Ca}^{2+}$ signal mediated by parallel fibre EPSPs, these first measurements of the $\mathrm{Ca}^{2+}$ current kinetics elucidate a quite precise timing of occurrence of the $\mathrm{Ca}^{2+}$ source that may eventually provide a less ambiguous explanation of the precise function of this spread dendritic depolarisation. In summary, the examples illustrated in this section show the potentials of this novel optical method in providing physiological information not available by using electrode techniques.

\section{Data interpretation and future prospective}

The method described here has been developed to overcome the limitations of single-electrode or two-electrode voltage clamp techniques permitting the analysis of physiological $\mathrm{Ca}^{2+}$ currents of native $\mathrm{Ca}^{2+}$ channels. Indeed, in contrast to patch-clamp recordings, these $\mathrm{Ca}^{2+}$ optical currents can 
be measured in conditions of a physiological change of $V_{m}$ and the measured currents are confined to the sites where they are recorded, as shown in apical dendrites of hippocampal pyramidal neurons (32). The additional information on local $V_{m}$ change, necessary to correlate the behaviour of the conductance with its biophysical properties, is obtained by combining VSD imaging. In cases of linear behaviour between $\mathrm{Ca}^{2+}$ influx and $\mathrm{Ca}^{2+}$ fluorescence changes the kinetics of the $\mathrm{Ca}^{2+}$ current can be extracted by calculating the time derivative of the $\mathrm{Ca}^{2+} \Delta \mathrm{F} / \mathrm{F}_{0}$ signal using low-affinity $\mathrm{Ca}^{2+}$ indicators $(11,16)$. In the case of nonlinear behaviour between $\mathrm{Ca}^{2+}$ influx and $\mathrm{Ca}^{2+}$ fluorescence, produced by $\mathrm{Ca}^{2+}$-binding proteins with slower kinetics with respect to the $\mathrm{Ca}^{2+}$ current, the kinetics of the $\mathrm{Ca}^{2+}$ current can be still correctly estimated by taking into account the faster unbinding of $\mathrm{Ca}^{2+}$ from the low-affinity indicator (24). In this last section we address the question of how data, obtained using this technique, should be interpreted. In $\mathrm{Ca}^{2+}$ current recordings from channels expressed in heterologous systems using voltage clamp, $\mathrm{V}_{\mathrm{m}}$ is controlled artificially and its change is therefore independent of the channel deactivation. Under physiological conditions, $\mathrm{Ca}^{2+}$ channels contribute to the $\mathrm{V}_{\mathrm{m}}$ change directly, through the ion flux, and indirectly by regulating other conductances. It follows that the channel deactivation changes the $\mathrm{V}_{\mathrm{m}}$ waveform. We have shown that in CA1 hippocampal pyramidal neurons this phenomenon produces a modulation of LVA-VGCCs by HVA-VGCCs (32). More in general, a $\mathrm{Ca}^{2+}$ current mediated by diverse VGCCs is always the result of a synergy among all different ion channels contributing to the $V_{m}$ waveform. It follows that in a $\mathrm{Ca}^{2+}$ current optical measurement, a single component of the current cannot be extracted simply by blocking the underlying channel, since this block may affect the residual current as well. This evidence has important implications in the study of transgenic animals carrying $\mathrm{Ca}^{2+}$ channel mutations. In this case, a certain phenotype is likely to result from the combined modification of function of many different channels, rather than from the specific $\mathrm{Ca}^{2+}$ influx component, making the study of these animals as models for disease challenging. In summary, the investigation of the role and function of individual $\mathrm{Ca}^{2+}$ channels must be performed in the global context of activation of all channels participating to the local $\mathrm{V}_{\mathrm{m}}$ waveform.

Another important aspect of data interpretation is the relation of the kinetics of $\mathrm{Ca}^{2+}$ current with the putative molecular targets of $\mathrm{Ca}^{2+}$ ions entering the cell. While importance is normally given to possible molecular coupling between the $\mathrm{Ca}^{2+}$ channel and the $\mathrm{Ca}^{2+}$ binding protein, the kinetics of the $\mathrm{Ca}^{2+}$ current can be a potent selector of the molecular pathway which is activated. To illustrate this important concept we make use of computer simulations using the same theoretical framework for simple $\mathrm{Ca}^{2+}$-binding dynamics that we already used in the past (42). We imagine the possible activation of two proteins: a "fast" protein with $\mathrm{K}_{\mathrm{ON}}=5.7 \cdot 10^{8} \mathrm{M}^{-1} \mathrm{~s}^{-1}$ and $\mathrm{K}_{\mathrm{D}}=10 \mu \mathrm{M}$, expressed at the concentration of $500 \mu \mathrm{M}$; and a "slow" protein with $\mathrm{K}_{\mathrm{ON}}=4 \cdot 10^{8} \mathrm{M}^{-1} \mathrm{~s}^{-1}$ and $\mathrm{K}_{\mathrm{D}}=0.4 \mu \mathrm{M}$, expressed at the concentration of $100 \mu \mathrm{M}$. In the first case, shown in Fig. 7a, the cell is receiving a fast $\mathrm{Ca}^{2+}$ current with $\sim 2 \mathrm{~ms}$ total duration which binds first to the fast protein and later to the slow protein. In the second case, shown in Fig. 7b, the cell is receiving a slower $\mathrm{Ca}^{2+}$ current that is smaller in amplitude but that carries approximately the same amount of $\mathrm{Ca}^{2+}$. In this case the slow protein binds to $\mathrm{Ca}^{2+}$ with a slower kinetics but the amount of the fast protein binding to $\mathrm{Ca}^{2+}$ is less than half with respect 
to the first case. These simulations indicate that the ability to activate for a molecular pathway triggered by the fast protein strongly depends on the kinetics of the $\mathrm{Ca}^{2+}$ current. Thus, the approach described here should drastically improve our understanding of the physiological function of $\mathrm{Ca}^{2+}$ channels by providing the possibility to explore the biophysics of native channels during physiological activity locally within the complex neuronal architecture. The examples of combined $\mathrm{V}_{\mathrm{m}}$ and $\mathrm{Ca}^{2+}$ current optical measurements from CA1 hippocampal pyramidal neurons, olfactory bulb mitral cells and PNs reported here are representative of the types of exploration that can be performed using this novel approach.

\section{Acknowledment}

This work was supported by the Agence Nationale de la Recherche through three grants: 1. Grant WaveFrontImag, program number ANR-14-CE17-0006-01; 2. Labex Ion Channels Science and Therapeutics, program number ANR-11-LABX-0015; 3. National Infrastructure France Life Imaging "Noeud Grenoblois" ; and by the Federation pour la recherché sur le Cerveau (FRC) through the grant Espoir en tête (in partnership with Rotary France).

\section{References}

[1] Braubach O, Cohen LB, Choi Y (2015) Historical Overview and General Methods of Membrane Potential Imaging. Adv Exp Med Biol 859: 3-26

[2] Davies R, Graham J, Canepari M (2013) Light sources and cameras for standard in vitro membrane potential and high-speed ion imaging. J Microsc 251: 5-13

[3] Canepari M, Willadt S, Zecevic D, Vogt KE (2010) Imaging Inhibitory Synaptic Potentials Using Voltage Sensitive Dyes. Biophys J 98: 2032-2040

[4] Sakmann, B, Neher E (1986) Patch clamp techniques for studying ionic channels in excitable membranes. Annu Rev Physiol 46: 455-472

[5] Gray R, Johnston D (1985) Rectification of single GABA-gated chloride channels in adult hippocampal neurons. J Neurophysiol 54: 134-142

[6] Lester HA (1988) Heterologous expression of excitability proteins: route to more specific drugs? Science 241: 1057-1063

17] Guy HR, Conti F (1990) Pursuing the structure and function of voltage-gated channels. Trends Neurosci 13: 201-206

[8] Antic SD (2016) Simultaneous recordings of voltage and current waveforms from dendrites. J Physiol 594: 2557-2558.

[9] Williams SR, Mitchell SJ (2008) Direct measurement of somatic voltage clamp errors in central neurons. Nat Neurosci 11: 790-798. 
459

460

461

462

463

464

465

466

467

468

469

470

471

472

473

474

475

476

477

478

479

480

481

482

483

484

485

486

487

488

489

490

491

492

493

494

495

496

497

[10] Hodgkin AL, Huxley AF (1952) Currents carried by sodium and potassium ions through the membrane of the giant axon of Loligo. J Physiol 116: 449-472.

[11] Jaafari N, De Waard M, Canepari M (2014) Imaging Fast Calcium Currents beyond the Limitations of Electrode Techniques. Biophys J 107: 1280-1288

[12] Canepari M, Vogt K, Zecevic D (2008) Combining voltage and calcium imaging from neuronal dendrites. Cell Mol Neurobiol 58: 1079-1093

[13] Vogt KE, Gerharz S, Graham J, Canepari M (2011a) High-resolution simultaneous voltage and $\mathrm{Ca}^{2+}$ imaging. J Physiol 589: 489-494

[14] Vogt KE, Gerharz S, Graham J, Canepari M (2011b) Combining membrane potential imaging with L-glutamate or GABA photorelease. PLoS ONE 6: e24911

[15] Kao JP, Tsien RY (1988) Ca2+ binding kinetics of fura-2 and azo-1 from temperature-jump relaxation measurements. Biophys J 53: 635-639

[16] Jaafari N, Marret E, Canepari M (2015) Using simultaneous voltage and calcium imaging to study fast Ca2+ channels. Neurophotonics 2: 021010

[17] Canepari M, Odgen D (2006) Kinetic, pharmacological and activity-dependent separation of two $\mathrm{Ca}^{2+}$ signalling pathways mediated by type 1 metabotropic glutamate receptors in rat Purkinje neurons. J Physiol 573: 65-82

[18] Canepari M, Vogt, KE (2008) Dendritic Spike Saturation of Endogenous Calcium Buffer and Induction of Postsynaptic Cerebellar LTP. PLoS ONE 3: e4011

[19] Savitzky A, Golay MJE (1964) Smoothing and Differentiation of Data by Simplified Least Squares Procedures. Anal Chem 36: 1627-1639

[20] Nägerl UV, Novo D, Mody I, Vergara JL (2000) Binding kinetics of calbindin-D(28k) determined by flash photolysis of caged $\mathrm{Ca}(2+)$. Biophys $\mathrm{J}$ 79: 3009-3018

[21] Airaksinen MS, Eilers J, Garaschuk O, Thoenen H, Konnerth A, Meyer M (1997) Ataxia and altered dendritic calcium signalling in mice carrying a targeted nullmutation of the calbindin D28k gene. Proc Natl Acad Sci USA 94: 1488-1493

[22] Lee SH, Schwaller B, Neher E (2000) Kinetics of Ca2+ binding to parvalbumin in bovine chromaffin cells: implications for [Ca2+] transients of neuronal dendrites. J Physiol 525: 419432

[23] Schmidt H, Stiefel KM, Racay P, Schwaller B, Eilers J (2003) Mutational analysis of dendritic Ca2+ kinetics in rodent Purkinje cells: role of parvalbumin and calbindin D28k. J Physiol 551: 13-32

[24] Ait Ouares K, Jaafari N, Canepari M (2016) A generalised method to estimate the kinetics of fast $\mathrm{Ca}^{2+}$ currents from $\mathrm{Ca}^{2+}$ imaging experiments. J Neurosci Methods 268: 66-77

[25] Usowicz MM, Sugimori M, Cherksey B, Llinás R (1992) P-type calcium channels in the somata and dendrites of adult cerebellar Purkinje cells. Neuron 9: 1185-1199

[26] Isope P, Hildebrand ME, Snutch TP (2012) Contributions of T-type voltagegated calcium channels to postsynaptic calcium signaling within Purkinje neurons. Cerebellum 11: $651-665$ 
[27] Miyakawa H, Lev-Ram V, Lasser-Ross N, Ross WN (1992) Calcium transients evoked by climbing fiber and parallel fiber synaptic inputs in guinea pig cerebellar Purkinje neurons. $\mathrm{J}$ Neurophysiol 68: 1178-1189

[28] Yan P, Acker CD, Zhou WL, Lee P, Bollensdorff C, Negrean A, Lotti J, Sacconi L, Antic SD, Kohl P, Mansvelder HD, Pavone FS, Loew LM (2012) Palette of fluorinated voltage-sensitive hemicyanine dyes. Proc Natl Acad Sci USA 109: 20443-20448

[29] Willadt S, Canepari M, Yan P, Loew LM, Vogt KE (2014) Combined optogenetics and voltage sensitive dye imaging at single cell resolution. Front Cell Neurosci 8: 311

[30] Antic SD (2003) Action potentials in basal and oblique dendrites of rat neocortical pyramidal neurons. J Physiol 550: 35-50

[31] Bullen A, Saggau P (1998) Indicators and optical configuration for simultaneous high-resolution recording of membrane potential and intracellular calcium using laser scanning microscopy. Pflügers Arch 436: 788-796

[32] Jaafari N, Canepari M (2016) Functional coupling of diverse voltage-gated $\mathrm{Ca}(2+)$ channels underlies high fidelity of fast dendritic $\mathrm{Ca}(2+)$ signals during burst firing. J Physiol 594: 967983

[33] Loew LM, Simpson LL (1981) Charge-shift probes of membrane potential: a probable electrochromic mechanism for p-aminostyrylpyridinium probes on a hemispherical lipid bilayer. Biophys J 34: 353-365

[34] Djurisic M, Antic S, Chen WR, Zecevic D (2004) Voltage imaging from dendrites of mitral cells: EPSP attenuation and spike trigger zones. J Neurosci 24: 6703-6714

[35] Roth A, Häusser M (2001) Compartmental models of rat cerebellar Purkinje cells based on simultaneous somatic and dendritic patch-clamp recordings. J Physiol 535: 445-472

[36] Spruston N, Schiller Y, Stuart G, Sakmann B (1995) Activity-dependent action potential invasion and calcium influx into hippocampal CA1 dendrites. Science 268: 297-300

[37] Canepari M, Djurisic M, Zecevic D (2007) Dendritic signals from rat hippocampal CA1 pyramidal neurons during coincident pre- and post-synaptic activity: a combined voltage- and calciumimaging study. J Physiol 580: 463-484

[38] Bischofberger J, Jonas P (1997) Action potential propagation into the presynaptic dendrites of rat mitral cells. J Physiol 504: 359-365

[39] Sabatini BL, Regerh WG (1996) Timing of neurotransmission at fast synapses in the mammalian brain. Nature 384: 170-172.

[40] Stuart G, Häusser M (1994) Initiation and spread of sodium action potentials in cerebellar Purkinje cells. Neuron 13: 703-712

[41] Vogt KE, Canepari M (2010) On the induction of postsynaptic granule cell-Purkinje neuron LTP and LTD. Cerebellum 9: 284-290

[42] Canepari M, Mammano F (1999) Imaging neuronal calcium fluorescence at high spatio-temporal resolution. J. Neurosci. Methods 1999; 87:1 -11 
a
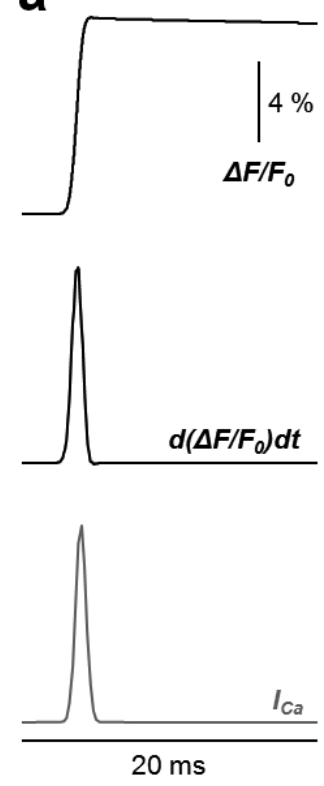

b

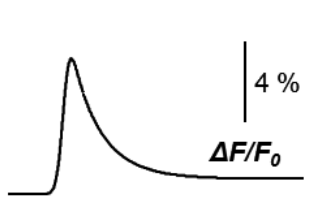

$-80$

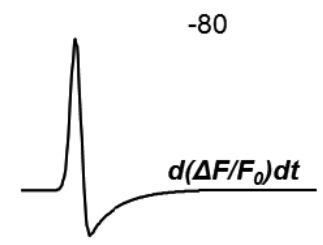

Fig. 1. Simulation of hypothetical $\mathrm{Ca}^{2+} \Delta \mathrm{F} / \mathrm{F}_{0}$ signals from 2 mM OG5N in the presence of endogenous $\mathrm{Ca}^{2+}$ buffers. (a) Simulation of $\Delta F / F_{0}$ signal (top trace) following a $\mathrm{Ca}^{2+}$ current with simple Gaussian kinetics ( $\mathrm{I}_{\mathrm{Ca}}$, gray trace on the bottom) in the presence of $1 \mathrm{mM}$ of a fast endogenous $\mathrm{Ca}^{2+}$ buffer with same association constant of the $\mathrm{Ca}^{2+}$ indicator $\left(5.7 \cdot 10^{8} \mathrm{M}^{-1} \mathrm{~s}^{-1}\right)$ and $\mathrm{K}_{\mathrm{D}}=10 \mu \mathrm{M}$. The kinetics of the $\Delta \mathrm{F} / \mathrm{F}_{0}$ time derivative (middle trace) matches the kinetics of the $\mathrm{Ca}^{2+}$ current. (b) Same as in the previous panel but in this case in the presence of additional $400 \mu \mathrm{M}$ of a slower buffer with association constant equal to $2 \cdot 10^{8} \mathrm{M}^{-1} \mathrm{~s}^{-1}$ and $\mathrm{K}_{\mathrm{D}}=0.2 \mu \mathrm{M}$. The kinetics of the $\Delta \mathrm{F} / \mathrm{F}_{0}$ time derivative (middle trace) does not matches the kinetics of the $\mathrm{Ca}^{2+}$ current. 


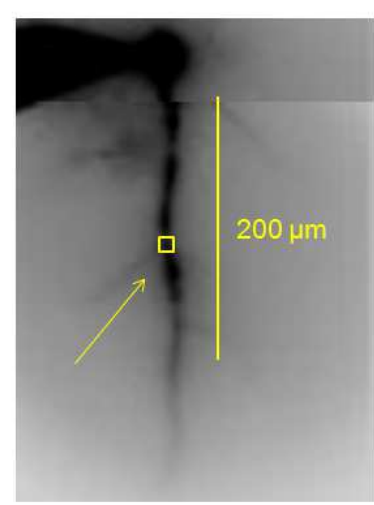

b

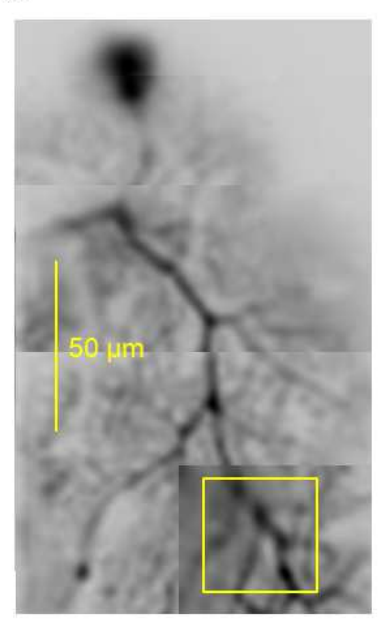

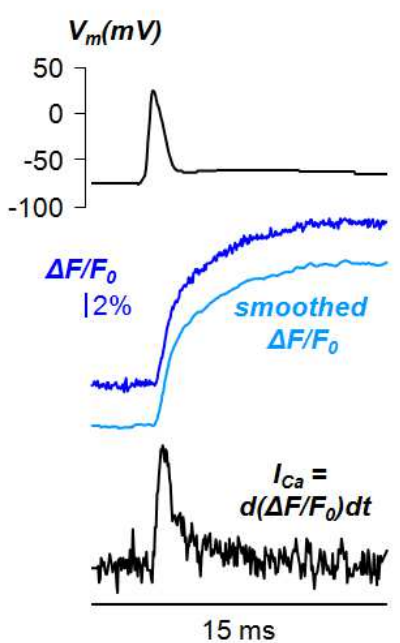
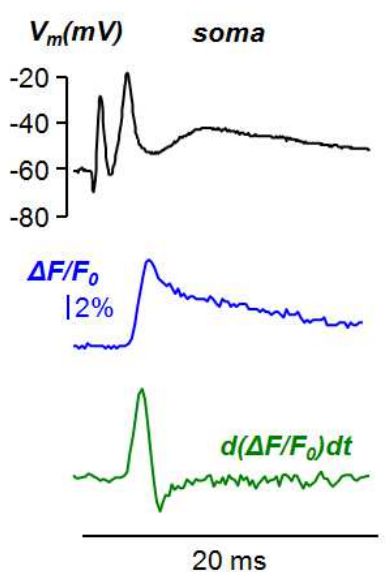

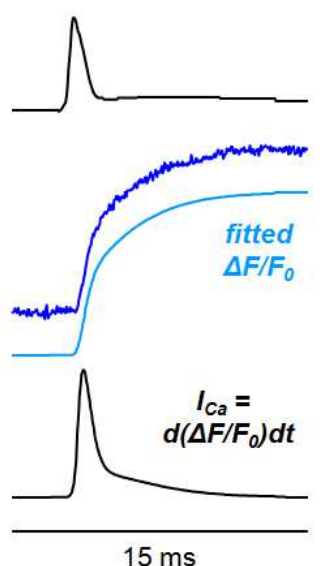

$15 \mathrm{~ms}$
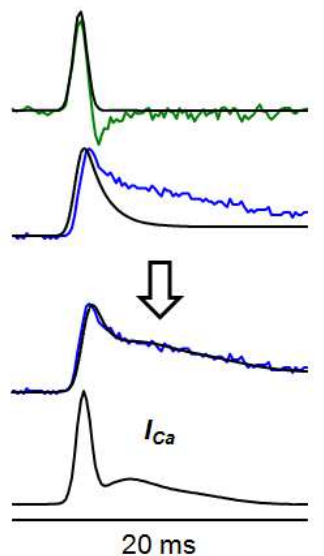

Fig. 2. Different strategies to estimate the kinetics of a $\mathrm{Ca}^{2+}$ current (a) On the left, fluorescence image of CA1 hippocampal pyramidal neuron filled with 2 mM OG5N with a small region of the apical dendrite outlined and indicated by the arrow. On the right, somatic $\mathrm{V}_{\mathrm{m}}$ change associated with an action potential (top black traces) and $\mathrm{Ca}^{2+} \Delta \mathrm{F} / \mathrm{F}_{0}$ signal in the indicated region (blue trace). The $\Delta \mathrm{F} / \mathrm{F}_{0}$ signal is either smoothed with a Savitky-Golay algorithm (left) or fitted with a 3-sigmoid function (right). The $\mathrm{Ca}^{2+}$ current kinetics $\left(\mathrm{I}_{\mathrm{Ca}}\right)$ is then estimated by calculating the time derivative of the processed $\Delta F / F_{0}$ signal. The kinetics of the current is the same using the two strategies, but the curve obtained with the strategy of data fitting is noiseless. Data, recorded at $20 \mathrm{kHz}$, were from averages of 16 trials. (b) On the left, fluorescence image of PN filled with $2 \mathrm{mM} \mathrm{OG5N}$ with square region of interest outlined. On the right, somatic $V_{m}$ change associated with a climbing fibre EPSP (top-left black trace) and $\mathrm{Ca}^{2+} \Delta \mathrm{F} / \mathrm{F}_{0}$ signal in the indicated region (blue traces). The time derivative of the $\mathrm{Ca}^{2+}$ $\Delta \mathrm{F} / \mathrm{F}_{0}$ signal (green traces) does not match the kinetics of the current. To estimate the kinetics of the current we use a strategy that consists in matching the result of a computer simulation to the $\mathrm{Ca}^{2+}$ $\Delta \mathrm{F} / \mathrm{F}_{0}$ signal using an optimised two-buffer model (24). We start from the Gaussian function fitting the rising phase of the $\Delta \mathrm{F} / \mathrm{F}_{0}$ time derivative (top-right black trace). We then correct the current with three additional Gaussian components until a match of the computer simulation with the $\mathrm{Ca}^{2+} \Delta \mathrm{F} / \mathrm{F}_{0}$ signal is obtained (process indicated by the arrow. The curve producing this match $\left(\mathrm{I}_{\mathrm{Ca}}\right.$, bottom-right black 
557

558

559

560

561

562

563

564

565

566

567

568

569

570

571

572

573

574

575

576

577

trace) is the estimate of the $\mathrm{Ca}^{2+}$ current kinetics. Data, recorded at $5 \mathrm{kHz}$, were from averages of 4 trials.

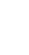
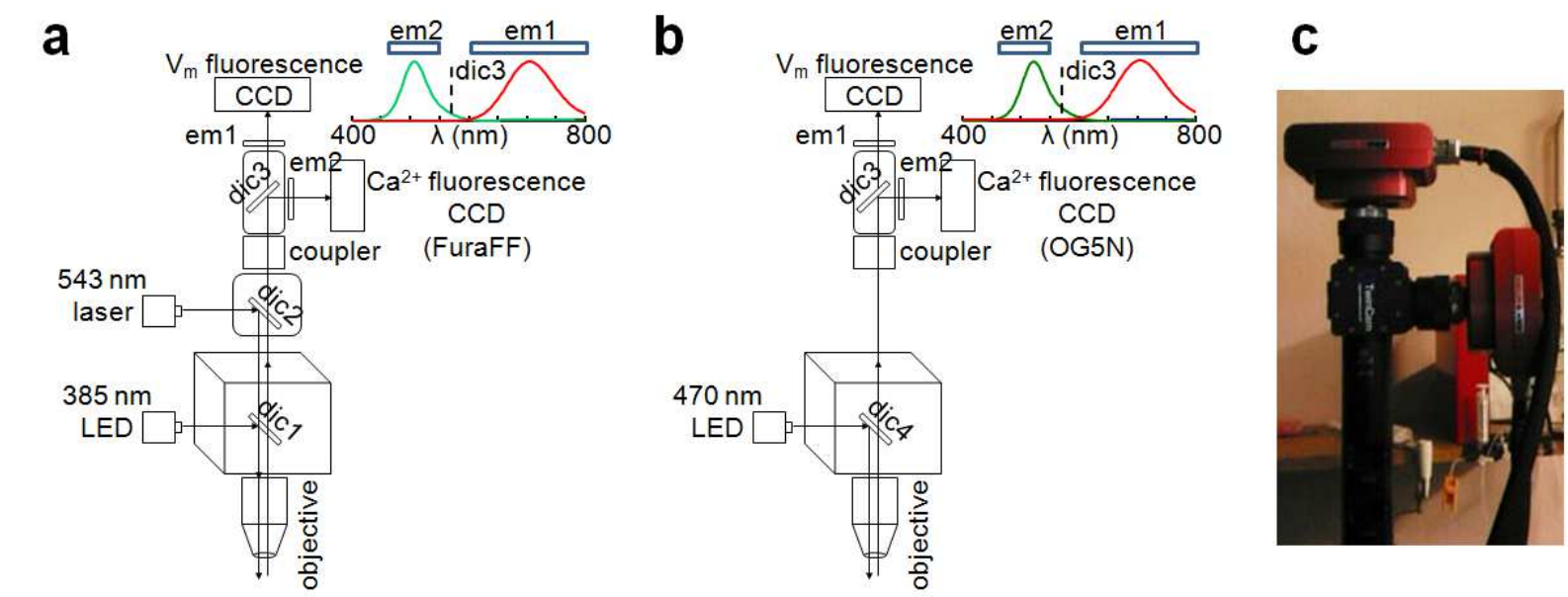

Fig. 3. Configurations and camera for combined voltage and $\mathrm{Ca}^{2+}$ fluorescence measurements. (a) Schematic drawing of the apparatus for simultaneous voltage and $\mathrm{Ca}^{2+}$ imaging using the VSD JPW1114 and the $\mathrm{Ca}^{2+}$ indicator FuraFF (13); $385 \mathrm{~nm}$ LED light via the epifluorescence port of a commercial microscope is reflected by a $506 \mathrm{~nm}$ long-pass dichroic mirror (dic1); $543 \mathrm{~nm}$ laser light via the top of the microscope is reflected by a dual-band dichroic mirror transmitting wavelengths between $493 \mathrm{~nm}$ and $530 \mathrm{~nm}$ and wavelengths longer than $574 \mathrm{~nm}$ (dic2); the fluorescence images of the two dyes are demagnified and separated by a $565 \mathrm{~nm}$ long-pass dichroic mirror (dic3); The $\mathrm{V}_{\mathrm{m}}$ image and the $\mathrm{Ca}^{2+}$ images are filtered by a $610 \mathrm{~nm}$ long-pass (em1) and by a $510 \pm 42 \mathrm{~nm}$ band-pass filter (em2) respectively, then acquired by two CCD cameras; the emission spectra of FuraFF (green) and JPW1114 (red) are shown on the top-right. (b) Schematic drawing of the apparatus for simultaneous voltage and $\mathrm{Ca}^{2+}$ imaging using the VSD JPW1114 and the $\mathrm{Ca}^{2+}$ indicator OG5N (11); $470 \mathrm{~nm}$ LED light via the epifluorescence port of a commercial microscope is reflected by a $495 \mathrm{~nm}$ long-pass dichroic mirror (dic4); the fluorescence images of the two dyes are demagnified and and processed as in the previous configuration; the emission spectra of OG5N (green) and JPW1114 (red) are shown on the top-right. (c) The dual NeuroCCD camera designed by Redshirtlmaging for this type of measurement. 


\section{a}

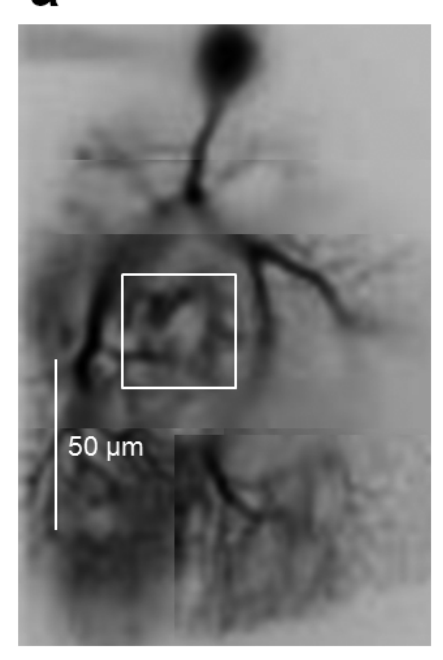

b

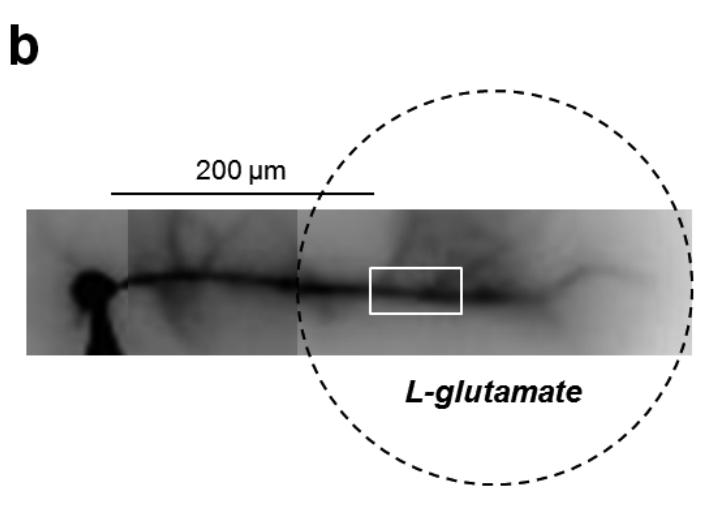

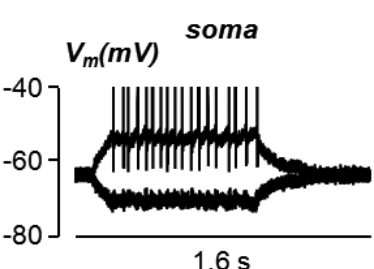
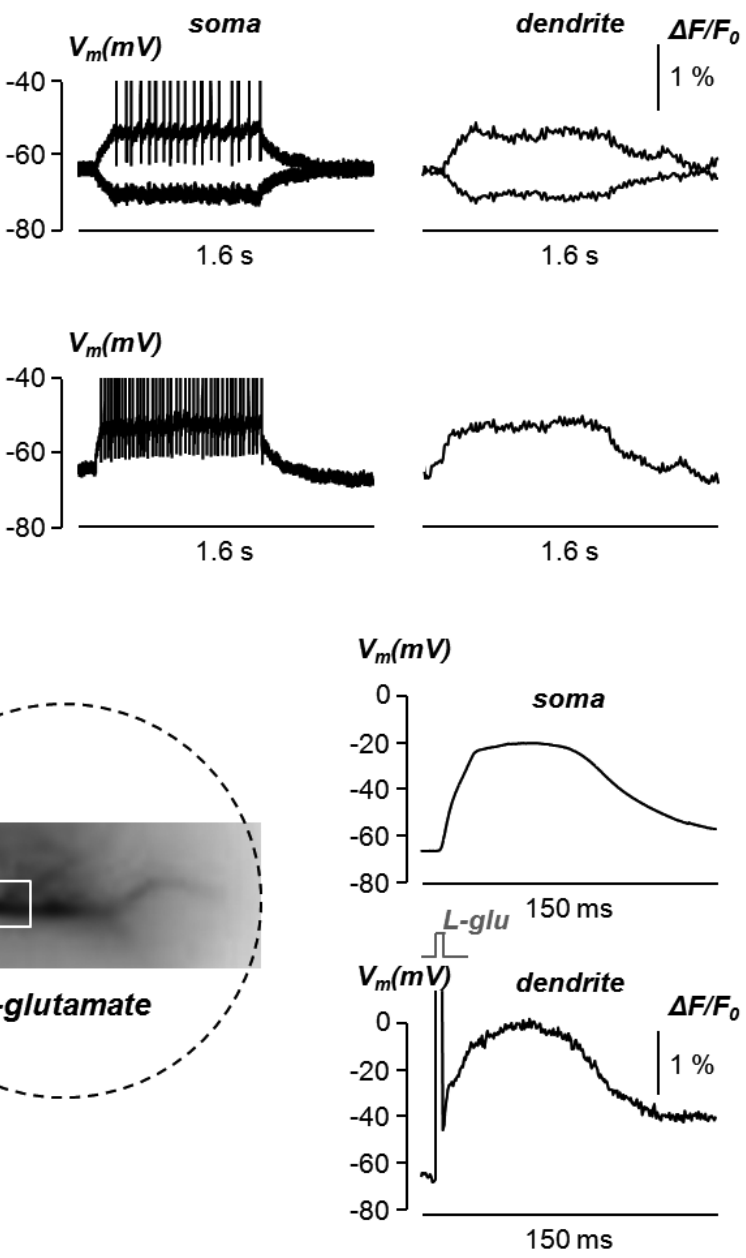

Fig. 4. Calibration methods for dendritic $V_{m}$ optical signals. (a) On the left, fluorescence image of PN with square region of interest outlined. On the right, somatic $V_{m}$ change associated with long hyperpolarising or depolarising steps and associated dendritic VSD $\Delta F / F_{0}$ signals in the region of interest; the hyperpolarising step spreads to the dendrites with negligible attenuation (35) and is used to calibrate the VSD $\Delta \mathrm{F} / \mathrm{F}_{0}$ signals; the weak depolarising step on the top also spreads with minimal attenuation, but the associated somatic action potentials do not propagate into the dendrites; in contrast, the strong depolarising step on the bottom attenuates. (b) On the left, fluorescence image of CA1 hippocampal pyramidal neuron with rectangular region, 200-250 $\mu \mathrm{m}$ from the soma, outlined. On the right, somatic $V_{m}$ change associated with L-glutamate photorelease from MNI-glutamate (14) in the area limited by the dotted line and in the presence of $1 \mu \mathrm{M}$ tetrodotoxin blocking action potentials; the dendritic VSD $\triangle \mathrm{F} / \mathrm{F}_{0}$ signal is reported on the bottom; the saturating L-glutamate concentration depolarises the illuminated area from the resting $V_{m}(\sim-70 \mathrm{mV})$ to the reversal potential of AMPA receptors $(0 \mathrm{mV})$. All calibrations were from single trials. 
a

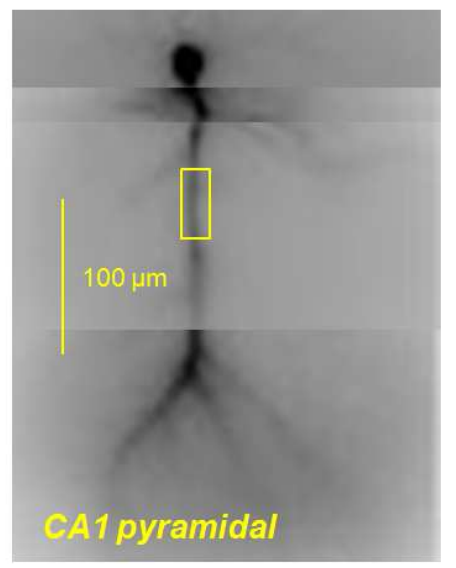

b

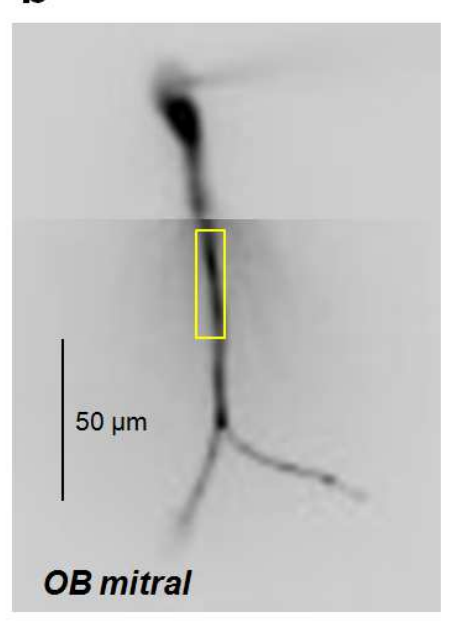

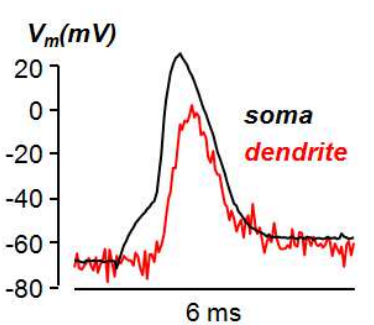
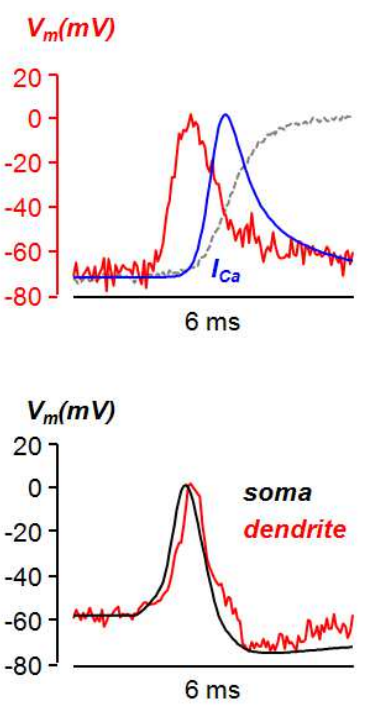

$V_{m}(m V)$

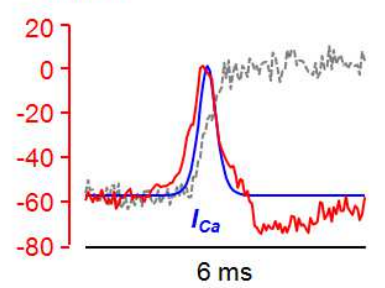

Fig. 5. $\mathrm{Ca}^{2+}$ currents associated with backpropagating action potentials in CA1 hippocampal pyramidal neurons and in olfactory bulb (OB) mitral cells (a) On the left, fluorescence image of CA1 hippocampal pyramidal neuron filled with JPW1114 and $2 \mathrm{mM}$ OG5N with a region of the apical dendrite outlined. On the right, somatic $V_{m}$ change associated with an action potential (black trace) in the soma and in the dendritic region. The associated $\mathrm{Ca}^{2+}$ current kinetics, obtained with the fitting strategy from the raw $\mathrm{Ca}^{2+}$ signal (dashed gray trace), is shown in the bottom. (b) On the left, fluorescence image of $O B$ cell filled with JPW1114 and $2 \mathrm{mM}$ OG5N with a region of the principal dendrite outlined. On the right, somatic $V_{m}$ change associated with an action potential in the soma (black trace) and in the dendritic region (red trace). The associated $\mathrm{Ca}^{2+}$ current kinetics, obtained with the fitting strategy from the raw $\mathrm{Ca}^{2+}$ signal (dashed gray trace), is shown in the bottom (blue trace) superimposed to the dendritic action potential (red trace). Data, recorded at $20 \mathrm{kHz}$, were from averages of 4 trials. All experiments were performed at $32-34{ }^{\circ} \mathrm{C}$.

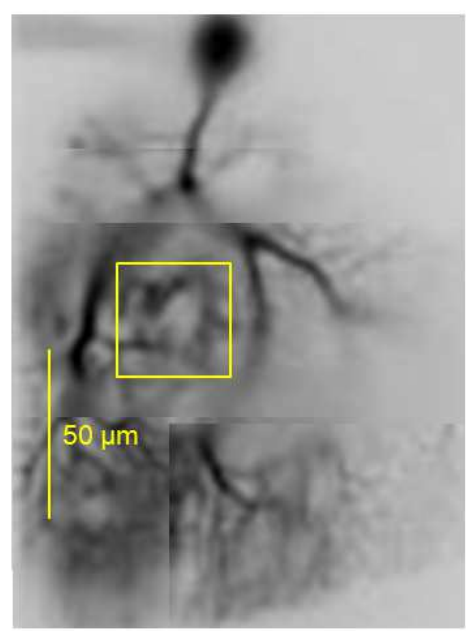

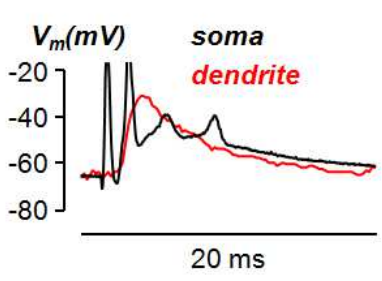

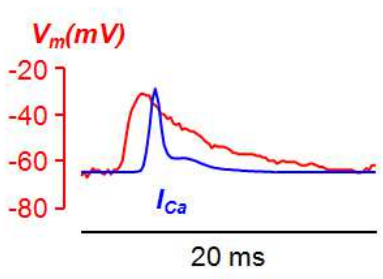

Fig. 6. $\mathrm{Ca}^{2+}$ currents associated with climbing fibre EPSPs in cerebellar Purkinje neurons. On the left, fluorescence image of PN filled with JPW1114 and 2 mM Fura-FF with a region of the dendrite outlined. On the right, somatic $V_{m}$ change associated with climbing fibre EPSP (black trace) in the soma and in the dendritic region. The associated $\mathrm{Ca}^{2+}$ current kinetics, obtained with the generalised method (24), is shown in the bottom. Data, recorded at $5 \mathrm{kHz}$, were from averages of 4 
trials. Experiments were performed at $32-34{ }^{\circ} \mathrm{C}$.

601

602

603
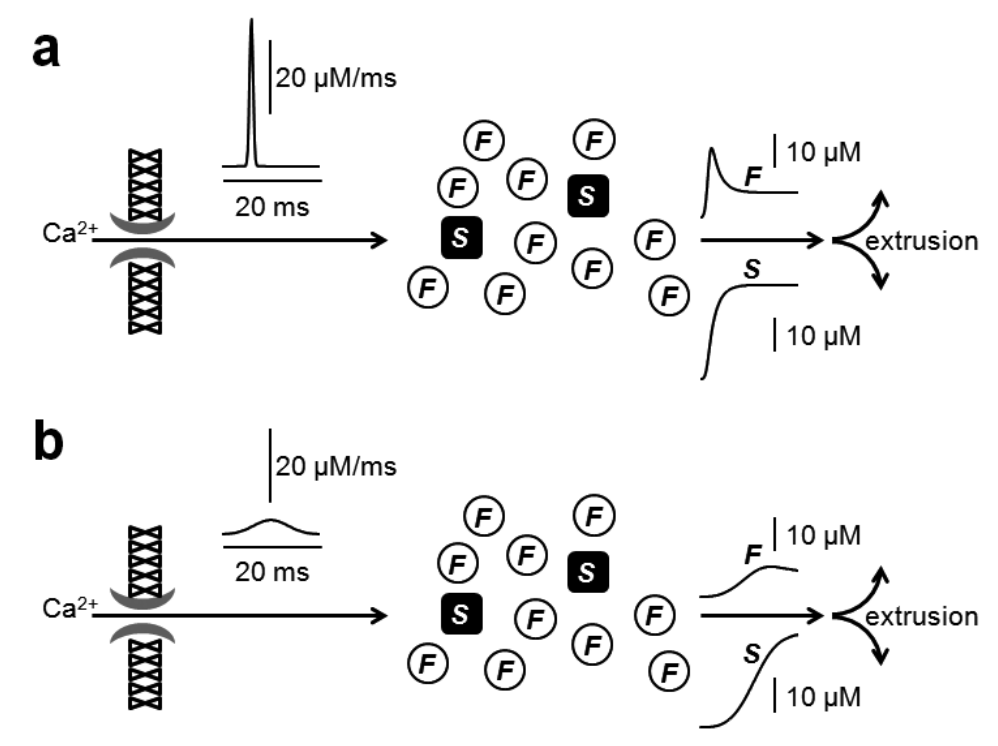

Fig. 7. Simulated activation of two different $\mathrm{Ca}^{2+}$-binding proteins by $\mathrm{Ca}^{2+}$ currents. (a) In a cell containing $500 \mu \mathrm{M}$ of a fast $(F)$ buffer with $\mathrm{K}_{\mathrm{ON}}=5.7 \cdot 10^{8} \mathrm{M}^{-1} \mathrm{~s}^{-1}$ and $\mathrm{K}_{\mathrm{D}}=10$ $\mu \mathrm{M}$, and $100 \mu \mathrm{M}$ of a slow (S) buffer with $\mathrm{K}_{\mathrm{ON}}=4 \cdot 10^{8} \mathrm{M}^{-1} \mathrm{~s}^{-1}$ and $\mathrm{K}_{\mathrm{D}}=0.4 \mu \mathrm{M}$, the curves on the right report the binding to $\mathrm{Ca}^{2+}$ of the $F$ and $S$ proteins following the fast $\mathrm{Ca}^{2+}$ current reported on the left. (b) Same as in the previous panel but following the fast $\mathrm{Ca}^{2+}$ current reported on the left.

604

605 